\title{
COMMENT
}

\section{The indirect effects of COVID-19 on pediatric research}

\author{
Stephen J. Teach ${ }^{1}$ and Joseph W. St. Geme III \\ Pediatric Research (2021) 90:246-247; https://doi.org/10.1038/s41390-021-01563-x
}

As members of the Research Committee of the Association of Medical School Pediatric Department Chairs, we write to comment on the review article by Fleming et al. ${ }^{1}$ on the consequences of the COVID-19 pandemic on child and adolescent health and associated research. We agree with many of the observations that the authors have highlighted, specifically the important needs for involving children in trials of COVID-19 vaccines and treatments, for natural history studies of youth who acquire COVID-19, for highly coordinated and collaborative clinical trials and cohort studies among academic institutions, for streamlining approaches to effective research governance and protection of research subjects while guaranteeing high levels of patient privacy and safety, and for the study of the unfortunate immediate sequelae of acute COVID-19 in children, specifically the postinfectious disorder called multisystem inflammatory syndrome in children, also referred to as Pediatric Inflammatory Multisystem Syndrome Temporally Associated with COVID-19.

In addition, we stress that investigators worldwide should focus on the indirect sequelae of the pandemic. For more than a year, it has radically changed the way children and adolescents live and interact with each other, all with the potential for long-term impacts on their physical and mental health. For example, what are the intermediate and long-term physical and behavioral health consequences of reduced social interactions, increased screen time, decreased physical activity, canceled sports seasons, and missed or virtual school? Already, pediatric mental health providers and emergency departments are facing increasing numbers of youth suffering from anxiety, depression, and suicidal ideation, as well as suicide attempts. ${ }^{2,3}$ Concerns are rampant ${ }^{4}$ that the prevalence of childhood obesity and malnutrition will rise further due to sedentary lifestyles ${ }^{5}$ and lack of access to schoolbased meal programs. ${ }^{6}$

The COVID-19 pandemic has also increased health and healthcare disparities for children and adolescents. ${ }^{7}$ This stems in part from the relationships between limited family resources and (1) access to the technology required for remote learning and for telemedicine visits, (2) ability to navigate the greater complexity of healthcare systems with COVID-19 constraints in place, and (3) opportunity for consistent parental supervision of home schooling. It is difficult to know how long it might take for youth who have fallen behind their peers in school to regain lost ground and what resources that they might require. Similarly, it is difficult to know the full impact of delays in healthcare on the progression of chronic diseases. All these issues need to be tracked and studied.

While the Children's Hospital Association and the American Academy of Pediatrics have called for expanded funding for existing programs addressing mental health, social isolation, academic underachievement, and other disorders (https://thehill.com/ business-a-lobbying/540148-childrens-hospitals-pediatricians-urgebiden-administration-to-prioritize and https://www.aappublications. org/news/2021/02/22/townhall-02-22-21), these health challenges also present opportunities for investigators to trial new and innovative solutions. The umbrella program entitled Collaboration to Assess Risk and Identify Long-Term Outcomes for Children with COVID (CARING for Children with COVID) (https://www.nih.gov/newsevents/news-releases/nih-effort-seeks-understand-mis-c-range-sarscov-2-effects-children), which is jointly sponsored by the Eunice Kennedy Shriver National Institute for Child Health and Human Development, the National Heart, Lung, and Blood Institute, and the National Institute for Allergy and Infectious Diseases and which encompasses a series of research networks, and the PreVAIL klds (https://www.nichd.nih.gov/newsroom/news/122120-prevail-kids) program focused on diagnostics for COVID-19 are encouraging starts. The Post-Acute Sequelae of SARS-CoV-2 Infection (PASC) Initiative (https://www.nih.gov/about-nih/who-we-are/nih-director/ statements/nih-launches-new-initiative-study-long-covid), recently announced by the National Institutes of Health, is another exciting step forward. While these programs will provide funding for infectious and postinfectious direct sequelae of COVID-19, we must stress that funds supporting investigators studying the myriad noninfectious, indirect sequelae of the pandemic on children are equally important.

As we race to increase our understanding of COVID-19 and SARS-CoV2, we must also acknowledge the importance of maintaining and initiating programs in non-COVID-19-related pediatric research. Much of this research has been slowed by the long pauses in research activity at academic and nonacademic institutions around the world at the height of the pandemic and by the redirection of research programs to a focus on COVID-19. Studies based in labs, clinics, and the community have all been delayed. Social distancing has also altered the fundamental context for translational studies as key outcomes like the incidence of respiratory infections and behavioral changes in school have radically changed. In the meantime, children continue to experience morbidity due to the full spectrum of pediatric diseases, underscoring the need for improved understanding of the pathogenesis of many pediatric diseases and for improved approaches to their diagnosis and treatment.

The COVID-19-associated pauses in research have the gravest implications for those at the start of their academic careers. Of greatest concern are the futures of those young investigators on time-limited career development awards (R38, T32, K08, K23, and others) who have lost critical months. Many of these young scientists are not generating the data necessary to transition to independent $\mathrm{R}$ awards. We strongly urge funded extensions of their awards through bridge programs like the one recently announced by the NIH that provides 1-year extensions on a case-

\footnotetext{
${ }^{1}$ Department of Pediatrics, Children's National Hospital, Washington, DC, USA and ${ }^{2}$ Department of Pediatrics, The Children's Hospital of Philadelphia, Philadelphia, PA, USA
} Correspondence: Stephen J. Teach (steach@childrensnational.org)

Received: 23 March 2021 Accepted: 30 March 2021

Published online: 7 May 2021 
The indirect effects of COVID-19 on pediatric research

SJ Teach and JWSt. GemellI

by-case basis to $\mathrm{K}$ awardees in the last year of their awards (https://grants.nih.gov/grants/guide/notice-files/NOT-OD-21-052.

html). We also urge the $\mathrm{NIH}$ to extend early-stage investigator status from 10 to 12 years or more (https://nexus.od.nih.gov/all/ 2020/04/09/can-esi-status-be-extended-due-to-disruptions-from-

covid-19/).

The COVID-19 pandemic has had an indelible impact on the health of children and adolescents and on the face of pediatric research. Nevertheless, with appropriate prioritization of resources by funding agencies and by academic and nonacademic institutions, we are optimistic that the broad consequences of COVID-19 will continue to wane, with an improved outlook on life for children and adolescents.

\section{AUTHOR CONTRIBUTIONS}

Both authors made substantial contributions to the conception and design of the manuscript and to drafting and revising it critically for important intellectual content. Both authors gave final approval of the version to be published.

\section{ADDITIONAL INFORMATION}

Competing interests: The authors declare no competing interests.
Patient consent: Not required.

Publisher's note Springer Nature remains neutral with regard to jurisdictional claims in published maps and institutional affiliations.

\section{REFERENCES}

1. Reference to Fleming manuscript when available.

2. Leeb, R. T. et al. Mental health-related emergency department visits among children aged $<18$ years during the COVID-19 pandemic - United States, January 1October 17, 2020. Morb. Mortal. Wkly Rep. 69, 1675-1680 (2020).

3. Hill, R. M. et al. Suicide ideation and attempts in a pediatric emergency department before and during COVID-19. Pediatrics 147, e2020029280 (2021).

4. Storz, M. A. The COVID-19 pandemic: an unprecedented tragedy in the battle against childhood obesity. Clin. Exp. Pediatr. 63, 477-482 (2020).

5. Verlenden, J. V., Pampati, S. \& Rasberry, C. N. Association of children's mode of school instruction with child and parent experiences and well-being during the COVID-19 pandemic - COVID experiences Survey, United States, October 8-November 13, 2020. Morb. Mortal. Wkly Rep. 70, 369-376 (2021).

6. Kinsey, E. W. et al. School closures during COVID-19: opportunities for innovation in meal service. Am. J. Public Health 110, 1635-1643 (2020).

7. Gati, S. B., Bloomhardt, H. M. \& McArthur, E. A. COVID-19: widening health disparities among pediatric populations. Am. J. Public Health 110, 1358-1359 (2020). 